\section{BMJ Paediatrics Open}

\title{
Identifying vulnerable children's stress levels and coping measures during COVID-19 pandemic in Japan: a mixed method study
}

\author{
Hajime Takeuchi (D) , ${ }^{1,2}$ Sharanya Napier-Raman, ${ }^{3}$ Osamagbe Asemota, ${ }^{4}$ \\ Shanti Raman (i) ${ }^{5}$
}

To cite: Takeuchi H, Napier-Raman S, Asemota 0, et al. Identifying vulnerable children's stress levels and coping measures during COVID-19 pandemic in Japan: a mixed method study. BMJ Paediatrics Open 2022;6:e001310. doi:10.1136/ bmjpo-2021-001310

\section{- Additional supplemental material is published online only. To view, please visit the} journal online (http://dx.doi.org/ 10.1136/bmjpo-2021-001310).

Received 3 October 2021 Accepted 20 January 2022

Check for updates

\section{(c) Author(s) (or their} employer(s)) 2022. Re-use permitted under CC BY-NC. No commercial re-use. See rights and permissions. Published by BMJ.

${ }^{1}$ School of Social Welfare, Bukkyo University, Kyoto, Japan 2Department of Epidemiology and Global Health, Umeå University, Umeå, Sweden ${ }^{3}$ School of Medicine and Health Sciences, University of Sydney, Sydney, New South Wales, Australia

${ }^{4}$ Department of Paediatrics, University of Calabar Teaching Hospital, Calabar, Nigeria ${ }^{5}$ Department of Community Paediatrics, South Western Sydney Local Health District, Liverpool, New South Wales, Australia

Correspondence to Professor Hajime Takeuchi; takechanespid@gmail.com

\section{ABSTRACT \\ Background The COVID-19 pandemic has} disproportionately affected vulnerable children and youth. In Japan, despite evidence that the paediatric age group holds a lower risk of infection than the older population, there was a nationwide closure of schools as an early public health measure. Acknowledging that school closures brought heightened psychological and physical stress among Japanese children, we aimed to explore vulnerable children's experiences of the COVID-19 pandemic in Japan, focusing on socially disadvantaged subset of the population.

Methods We used an adapted version of the 'Perceived Stress Scale for Children', with additional free-text space, delivered online to children attending three non-profit organisations which provide support for this group of vulnerable persons and families experiencing social disadvantage. Simple descriptive analysis was undertaken on the quantitative data; we used thematic and content analysis for the qualitative data.

Results Thirty-six children participated in the online survey, mean age was 11.3 years, majority $(61 \%)$ were male. The mean overall stress score (score distribution width: 0-39) was 14.8, with no difference in score distribution by age or gender. Free-text responses obtained revealed a range of stressors and protective factors. Schooling, COVID-19 fears, family tension and pandemic measures were sources of stress; family - in particular, the support of the mother-food, friendship and recreation were sources of comfort. While most responses indicated positive coping mechanisms, some displayed maladaptive behaviours.

Conclusions The children in this cohort had high mean stress scores overall. Responses indicated that they were acutely reactive to COVID-19 as well as pandemic public health measures, and that missing schooling and contact with friends exacerbated their stress. Family was a source of strength as well as stress. A tailored public health response to COVID-19 needs to take into account the concerns voiced by vulnerable child populations be based on equity and child rights.

\section{INTRODUCTION}

The emergence and spread of the SARS-CoV-2, or COVID-19 has had global ramifications,
What is known about the subject?

While children and young people are less likely to suffer direct impacts from COVID-19, they experience heightened adversity due to indirect effects and social control measures.

- In Japan, children were the earliest target of government-mandated pandemic measures with a closure of kindergartens and schools, even before implementing other measures.

- Early reports of COVID-19 effects on Japanese children include an increase in psychological distress, weight gain and increased maternal anxiety related to parenting.

\section{What this study adds?}

The small cohort of vulnerable children in Japan had high overall stress scores during the early part of the pandemic.

- Simple modifications of the Perceived Stress Scale for Children made it possible to rapidly assess the lived experience of COVID-19 measures in this group of people.

- School-related anxiety and concerns about infection were reported in this subset of vulnerable children along with resilience factors, particularly the role of mothers.

sparing no country or region. For children and young people (CYP), the impact of the COVID-19 pandemic is far more significant in terms of indirect effects than direct infections. Children hold lower infection risk and have, therefore, seen less mortality than adults but are vulnerable to the sweeping lifestyle changes and disruptions borne from a global pandemic. ${ }^{1}$ Global estimates hold that between 1 March 2020 and 30 April 2021, well over one million children experienced the death of a primary caregiver. ${ }^{2}$ Children faced mass school closures, with $80 \%$ of 
students out of school by March $2020 .{ }^{3}$ The significant mental health burden of the pandemic and associated restrictions on children have been noted. ${ }^{4}$ CYP from low income and minority backgrounds face greater barriers; the pandemic and resulting disruptions to everyday life, access to care and other services have magnified challenges for vulnerable populations. ${ }^{5-7}$

While Japan's COVID-19 experience has certainly been less severe than countries such as the USA and much of Europe, the pandemic and corollary public health measures have had immense impact in terms of direct health consequences and social and economic ramifications. ${ }^{8}$ With the surge in cases over July-August 2021, these consequences could be protracted. ${ }^{10}$ As has been the case globally, the burden on Japan's CYP has not been seen in infection rates, but in indirect effects of the pandemic and control measures. ${ }^{9}$ Indeed, despite evidence of children having lower infection risk than other age groups, CYP were at the forefront of Japan's pandemic response. ${ }^{11} 12$ In March 2020, without implementing any other measures, the Japanese government instituted a sudden nationwide closure of schools and kindergartens. ${ }^{11} 12$ Along with obvious impacts of losing crucial socialisation and education, ${ }^{9}$ closures exposed children to heightened family tension, loss of support systems such as school lunch provision and increased health risks, including weight gain. ${ }^{11}$

Pandemic measures and health-system strain also expedited breakdown in many Japanese public healthcare services, including maternal and child care. ${ }^{13}$ This loss of support systems combined with lifestyle disruptions brought by school closures contributed to increased psychological and physical stress among Japanese CYP, these were mediated by parenting styles. ${ }^{9}$ While there are differences in which groups are considered 'vulnerable' depending on geography, CYP experiencing poverty, family dysfunction and neglect are recognised globally as priority populations. ${ }^{14}$ In Japan, detrimental impacts of pandemic measures on mental and physical health appear to be more severe among children from lower socioeconomic backgrounds; however, there were few studies focusing on vulnerable CYP's views and experiences. Our aims were, therefore, to explore CYP's experiences of the COVID-19 pandemic in Japan, focusing on stress levels in socially disadvantaged children, using a simple online tool with free text. We wanted to gauge CYP's responses to the pandemic in their own words.

\section{METHODS}

The study was conducted with the cooperation of three non-profit organisations, which provide support for children and families experiencing neglect, abuse and other socioeconomic difficulties: 'Shinmama Osaka Ouendan', 'Shinmama Ouendan Toyonaka' and 'CPAO'. 'Shinmama Osaka Ouendan' supports single-mother families by providing them with food, essential goods, welfare and housing support; this organisation operates locally and nationwide. 'Shinmama Ouendan Toyonaka' provides free meals and safe, comfortable spaces for children and social support for single mothers and families living in poverty. The essential supports provided by this organisation are the food bank and a safe space for children to spend after school. 'CPAO' also serves free meals and play areas, and has a house providing temporary shelter for children who cannot be housed with their families. A 'safe space' is where children can spend their time peacefully and comfortably with provision of meals and shelter. CYP who were regular beneficiaries of the three non-profit organisations were invited to participate by staff from the three organisations. Workers personally approached CYP and asked if they would be interested in participating in the online questionnaire, which described their experiences and feelings during the COVID-19 pandemic; researchers did not approach children directly. Workers approached approximately 10 CYP in Shinmama Osaka Ouendan, about 40 in Shinmama Ouendan Toyonaka and about 30 in CPAO. Children were given the QR code by the staff after parental consent was obtained and the children assented. Children without mobile phones were helped by parents to access the online questionnaire. Parents were encouraged to record their children's responses and not to interfere with questionnaire completion by offering suggestions or commenting on their choices. Some responses were completed on site in the not-for-profit building, while others were completed at home. Data gathering occurred between August and November in 2020, during partial school closure with staggered attendance and other pandemic measures. We deliberately did not have inclusion and exclusion criteria, since we wanted to encourage full voluntary participation. CYP were assured of anonymity, and no coercion or incentives were provided to encourage participation.

\section{Instrument}

The tool was adapted from the 'Perceived Stress Scale for Children' (PSS-C), developed by White. ${ }^{15}$ We chose the PSS-C, because it is an easy to use tool for children, brief, efficient, validated and ideally suited for online application. With White's permission, the PSS-C was modified (online supplemental figure 1), and translated into Japanese. The modification made to the scale was asking about participants' experiences 'during the COVID-19 pandemic' instead of 'in the last week'. Additionally, open-ended 'free description' versions of each question were added to collect qualitative data on CYP's experiences. Participants completed the questionnaire online via Google Forms.

The PSS-C comprises 14 questions targeting key areas of childhood stress perception, including experiences of time pressure, concerns about grades, parental relationships, feelings of fear, anger and happiness, sleep and friendship. Responses were scored as follows: 'Never' 0 point, 'A little' 1 point, 'Sometimes' 2 points, and 'A lot' 3 points. Seven questions were reverse scored as per the original PSS-C, ${ }^{15}$ to increase the likelihood of truthful 
responding. Higher total scores indicated higher stress perception. Four composite scores were aggregated as the following variables: stressor sensitivity (questions 2, 4, 5, 8, 9 and 12); emotional state (questions 8, 9, 10 and 12); security (questions 6 and 7)-higher scores indicating greater insecurity; and time pressure (questions 2, 3 and 4).

Free-text responses were translated and transcribed into English by the first author.

\section{Analysis}

Simple descriptive analysis on the quantitative data was carried out using Stat View. Free-text descriptions were analysed using $\mathrm{KH}$ Coder for content analysis and text mining based on the original responses in Japanese. ${ }^{16}$ Additionally, we undertook thematic analysis of the translated free-text responses. ${ }^{17}$ Analysis of the qualitative data was ongoing and iterative; we finally triangulated the findings from the quantitative and qualitative analysis to arrive at a more nuanced understanding of CYP's experiences.

\section{Patient and Public Involvement}

The authors have extensive experience working with vulnerable child and youth populations. The first author has strong links with the three non-profit organisations servicing CYP experiencing social disadvantage, where this study was conducted. The research questions and outcome measures were based on the emerging literature on children's experiences of COVID-19, the authors' clinical and research experience and the relationship with the community-based sector. While CYPs were not involved in the design of the study, they provided active consent and participated of their own free will.A summary of the findings from the study in Japan was provided to the three organisations, who were encouraged to disseminate to CYP attending their services.

\section{RESULTS}

\section{Quantitative}

Thirty-six children participated, 30 answered all questions and 6 completed partially. The average age of participants was 11.3 years (range: 8-17 years). Majority of respondents were male $(22 ; 61 \%), 13$ were female $(36 \%)$ and 1 did not specify gender. The results of stress scores for all children are listed in table 1 . The mean of the overall stress score (score distribution width: 0-39) was 14.8; 16 respondents $(53 \%)$ had moderate stress scores and 11
$(36 \%)$ had high stress scores. There was no difference in score distribution by age or gender.

\section{Qualitative findings}

Free-text responses revealed a range of stressors and protective factors. Not all children answered free-text responses to every question, only one completed all questions.

\section{Stressors}

School related

'tired because I don't have a day off'

School was mentioned by many respondents to questions about what made children feel rushed (Q2), busy (Q3), scared (Q8) and angry (Q9). Schoolwork was the most frequently listed factor contributing to time pressure. Children's concerns about schooling included entrance exams, pressure to study and increased workloads. In response to what made them worried about school (Q5), children described 'endless' work, not having 'done anything except homework', being concerned about grades and falling behind. Children also held concerns about school closure and its implications. In response to what made them feel scared or nervous, one child listed feeling 'miserable' because school closure meant that they had 'nothing to do'. Children reported being 'afraid ... the school will be closed again', 'worried about the future' and unsure whether they would be able to return to school or proceed into high school.

\section{COVID-19 fears}

"scared' they had caught COVID-19'

Fear about infection was evident in many of the responses. Of the 13 children who answered what made them feel scared or nervous, 8 mentioned COVID-19 or infection. Worry about COVID-19 also contributed to poor sleep. Children were mostly concerned that they themselves would be infected, though some mentioned being scared for family and friends. There were also fears about the 'constantly increasing number' of cases and celebrity infections. One participant expressed anger at people who 'seemed not to think very well', holding large gatherings and becoming infected.

However, one respondent reported being 'happy' at the prospect 'humankind would be destroyed' and was 'disappointed' that the virus 'wasn't so much deadly'.

\section{Family tensions}

'my siblings disturbed me and used violence while I was playing in a good mood'

Table 1 Stress scores in a group of socially disadvantaged Japanese children aged 8-17 years ( $n=36)$, as assessed by the Perceived Stress Scale for Children

\begin{tabular}{llllll}
\hline & Stress score & Stressor sensitivity & Emotional state & Security & Time pressure \\
\hline Mean (SD) & $14.8(4.6)$ & $10.6(3.4)$ & $4.8(2.7)$ & $3.3(2.1)$ & $2.6(2.2)$ \\
Median & 14 & 10 & 4 & 3 & 2 \\
\hline
\end{tabular}


Tensions among family members, particularly siblings, were evident in several responses. While parentsespecially mothers-were typically a source of support, siblings were consistently mentioned in negative emotion questions (what made you angry? and why did you have fights?). Seven children mentioned 'quarrelling' with siblings, with two responses describing physical violence. Interactions with siblings were the most common response to what made children angry during the pandemic. No children mentioned siblings making them happy or playing with them. One child did say, 'she [mother] is always angry'.

\section{Pandemic measures}

'banished and killed ... by the masked people'

Over half the responses to what made children angry were related to pandemic-related measures. Children were angry that they were not 'able to play with friends' or 'go out'. Many described the loss of things they had been looking forward to: curtailment of summer holidays, cancellations of school camps and 'an anime I was looking forward to', being unable to visit family.

A number of participants described masks as causing fear and frustration. In response to what made them angry, two children mentioned 'wearing a mask' and another reported being harassed by schoolmates when their mask was out of place. One participant described going out unmasked and people being 'disgusted'. A 13-year-old boy who was unhappy about schools reopening due to infection fears was nevertheless 'angry at wearing a mask all the time'. One participant displayed disenchantment with the handling of the pandemic, stating 'the government is incompetent, and WHO's messages are two-faced'. No children mentioned lack of foods or essentials, though one did mention that COVID-19 financial support made them happy, allowing them to 'go to a cram school for private supplementary lessons after school hours and have an air conditioner in my room'.

\section{Protective factors}

Family

'my mother told me that I was okay when I was worried'

Mothers were the source of much comfort for children. In responses to questions 6 and 7, who made you feel better and loved, 22 responses referred to mothers. KH Coder analysis of question 6 found 'mother' was recalled with words such as 'feeling', 'good' or 'like'. Five children described how their mother 'took care' of them, and three said that their mothers took them to 'enjoyable places' such as the 'spa' or 'theme park' to make them feel better. Other responses included mothers 'spoke kindly', 'listened to me carefully', 'played with me' and 'encouraged me'.

Mothers also mitigated stressors, particularly arising from school. Mothers did not reprimand children for being unable to study and reminded them not 'to study too much'. One child described how their mother 'thought a lot to change my dark mood' and, instead of going out with her friends, stayed at home with her child because they were stuck studying at home.

KH Coder analysis found the terms 'mother', 'game' and 'outside' were frequently paired together in responses to what children did. Some children also mentioned fathers and 'family' as positive factors. Responding to who made them feel better, one child mentioned that their family taking a day off together and another described how their father 'checked games' for them, meaning their fathers monitored their games to ensure that they did not spend too much time on them. Spending time with family was something that made children feel happy.

\section{Food}

'my mother made sure I didn't eat alone while the school was closed'

Food-related responses were common among answers to who made children feel better and loved. Children mentioned, 'eating out' and 'cooking' as things that made them feel better or happy. Mothers were again significant in these protective factors, cooking 'delicious dishes' for children and buying ingredients for sweets.

\section{Recreation and time with friends}

'school closure made me a lot of free days'

Playing games was most commonly listed by children as what they spent time doing, and what made them happy. When asked what they spent time doing, 15 responses included 'playing games' or 'playing outside'. Children reported playing by themselves or with friends or neighbours. KH Coder analysis of responses to who children played with and how, found the words 'outside' and 'play', 'school', and 'friends' were associated. Children described interacting with friends virtually and in-person across a range of media.

Some children indicated a lack of friends. One child played 'alone' and two children responded that they did not fight with friends because they did not 'have any friends' or play much with friends to begin with.

Other common responses to how children spent time were drawing/colouring pictures, watching TV or YouTube and reading books or manga (Japanese comic book). Some children also stated that they were happy that 'school was closed'. KH Coder analysis found the words 'games', 'holidays', 'COVID-19' and 'schools' were the most frequently used to describe what made children happy. Children noted having more time for hobbies and leisure. Responses included: 'I could colour pictures because of school closure' and 'time increased with family at parks or shopping'.

\section{Outliers}

Occasional responses from children displayed maladaptive responses. When asked what made them happy, one 17-year-old said, 'I was happy when I could imagine that humankind would be destroyed by the COVID-19 pandemic'. 


\section{DISCUSSION}

Despite the resurgence of COVID-19 cases, Japan's Ministry of Health, Labour and Welfare in Japan has asserted that children remain relatively spared. ${ }^{8}$ Our study documents the responses of a specific group of socioeconomically vulnerable Japanese children to the COVID-19 pandemic and related public health measures. Japanese children in this cohort had high mean stress scores overall. Children in this study reported that schooling, COVID-19 fears, family tension and pandemic measures were sources of stress, while family, food, friendship and recreation were sources of comfort.

While the direct influence of COVID-19 on children in Japan has been minor, indirect burdens of the pandemic have become significant problems. Our study findings were not dissimilar to other recent studies of children's responses to COVID-19. Yamaguchi et al's very large study using an online survey found that children's rights had been restricted during the pandemic, children's most frequent concern was COVID-19 infecting family members, followed by the inability to see their friends. ${ }^{18}$ A survey in Okinawa prefecture reported the effects on children's learning performance, extracurricular activities and stress associated with friendships due to school closures and subsequent restrictions on their lives. ${ }^{19}$ The CORONA $\times$ CODOMO survey conducted to gather the voices of children and families under the COVID-19 pandemic found that parents and children exhibited features of depression, but children also displayed ingenuity in dealing with the situation. ${ }^{20}$ Mochida et als study of parents with young children found that while children displayed increased stress signs, they also showed increase in positive behavioural traits during this period. Children's stress was modified by parental behaviour-a warm and permissive parenting style had positive correlations with good behavioural traits. ${ }^{9}$

Children's major stressors in this study were schoolrelated and pandemic fears. Their countermeasures were remote games and direct indoor and outdoor play with friends and connections via social media. Support from family, especially mothers, and the comforting role of food were evident. Quarrelling and fighting increased with siblings, making family a source of support as well as stress. Other international studies exploring CYP's voices during the COVID-19 pandemic have also revealed increased psychological stress and family tensions, counterbalanced by positive coping strategies. ${ }^{21} 22$ Disturbingly, there were a small number of aberrant responses that suggested increased vulnerabilities, not buffered adequately by available supports.

The COVID-19 pandemic has highlighted how infection measures and school closures impact children's well-being. There is ample evidence that school closures are harmful to CYP's mental health, ${ }^{23}{ }^{24}$ worsen educational outcomes, ${ }^{25}$ exacerbate inequities in learning outcomes ${ }^{26}{ }^{27}$ reduce future earnings significantly ${ }^{28}$ and are unethical in light of the very limited data of public health benefit. ${ }^{29} \mathrm{~A}$ recent systematic review of
COVID-19-related school closures concluded that school closure and lockdown have adverse effects on child health and well-being in the short term and probably long term. ${ }^{30}$ The Japanese government's early adoption of school closures as a public health measure is clearly not supported by evidence. Children in our study were very concerned about missing school, with the added pressure of catching up academically, and missing social interaction. Stress scores did not differ by age or gender, suggesting that the COVID-19 pandemic and accompanying school closure experience placed burdens on every child.

The major limitation of this study was the small number of children who responded to the survey. There were also missing data due to the questions that were not answered fully. Results are, therefore, not generalisable to all Japanese children, nor all CYP experiencing adversities. It is possible that CYP in particularly difficult situations did not express themselves in free text; we have to read between the lines about what was not verbalised and described. We also modified with the author's permission the PSS-C timescale on which children were asked to report-during the COVID-19 pandemic as opposed to the past week. We do not know if asking them about their experiences over a longer period versus just over the past week would have avoided recall bias. We are aware that CYP's stress levels may have varied over the pandemic, depending on a range of factors; and since this was a onepoint survey, we would recommend follow-up data collection to provide a more holistic picture.

\section{CONCLUSIONS}

The impact of the COVID-19 pandemic on a small cohort of Japanese CYP experiencing social disadvantage was analysed using a simple modified online tool, with opportunities for CYP to voice their experiences and concerns. Acknowledging that our study sample was small, our results nevertheless show that the pandemic placed a great deal of stress on this cohort of vulnerable CYP. While many children experienced difficulties, many showed positive coping, being supported by family relationships and friends. However, a small number of children exhibited poor coping. We advocate that a public health response to COVID-19 should be responsive to the needs and concerns voiced by CYP, be evidence-informed with respect to school closures and most importantly, be based on equity and child rights.

\section{Twitter Hajime Takeuchi @takechan1024}

Acknowledgements Great thanks go to Barbara P White, Department of Professor, University of New Hampshire, for the acceptance of the rearrangement of the original questionnaire for COVID-19 pandemic. Thanks go also to the three organisations and children who cooperated in the survey. We acknowledge the strong support of the International Society for Social Paediatrics and Child Health's COVID-19 Research Group members for their ongoing advice and collaboration. A key benefit of this group was the coming together of researchers, clinicians and child health advocates from across the world, sharing tools that could be used and modified rapidly in different settings to understand children and young people's experiences of COVID-19. 
Contributors HT contributed to the conception and design of this work, acquiring, analysing and interpreting data, and writing important intellectual content and approved the final version. SN-R contributed to the analysis, interpretation of data, writing and approved the final version. OA contributed to the critical proofreading of intellectual content and approved the final version. SR contributed to the analysis, interpretation of data, was involved in the critical proofreading of important intellectual content and approved the final version. HT acts as guarantor.

Funding This work was supported by the Japanese Society for Promotion of Science (grant number: 17K04280).

Competing interests No, there are no competing interests.

Patient consent for publication Not applicable.

Ethics approval This study involves human participants and was approved by Bukkyo University's Human Research Ethics Review Committee (approval number: 2020-6-A). Participants gave informed consent to participate in the study before taking part.

Provenance and peer review Not commissioned; externally peer reviewed.

Data availability statement Data are available in a public, open access repository. Not applicable.

Supplemental material This content has been supplied by the author(s). It has not been vetted by BMJ Publishing Group Limited (BMJ) and may not have been peer-reviewed. Any opinions or recommendations discussed are solely those of the author(s) and are not endorsed by BMJ. BMJ disclaims all liability and responsibility arising from any reliance placed on the content. Where the content includes any translated material, BMJ does not warrant the accuracy and reliability of the translations (including but not limited to local regulations, clinical guidelines, terminology, drug names and drug dosages), and is not responsible for any error and/or omissions arising from translation and adaptation or otherwise.

Open access This is an open access article distributed in accordance with the Creative Commons Attribution Non Commercial (CC BY-NC 4.0) license, which permits others to distribute, remix, adapt, build upon this work non-commercially, and license their derivative works on different terms, provided the original work is properly cited, appropriate credit is given, any changes made indicated, and the use is non-commercial. See: http://creativecommons.org/licenses/by-nc/4.0/.

ORCID iDs

Hajime Takeuchi http://orcid.org/0000-0002-2368-5087

Shanti Raman http://orcid.org/0000-0002-4546-3231

\section{REFERENCES}

1 UNICEF. Policy brief: the impact of COVID-19 on children. New York: United Nations Children's Fund, 2020.

2 Hillis SD, Unwin HJT, Chen Y, et al. Global minimum estimates of children affected by COVID-19-associated orphanhood and deaths of caregivers: a modelling study. Lancet 2021;398:391-402.

3 Takaku R, Yokoyama I. What the COVID-19 school closure left in its wake: evidence from a regression discontinuity analysis in Japan. $J$ Public Econ 2021;195:104364.

4 Creswell C, Shum A, Pearcey S, et al. Young people's mental health during the COVID-19 pandemic. Lancet Child Adolesc Health 2021;5:535-7.

5 Ahmed F, Ahmed Na'eem, Pissarides C, et al. Why inequality could spread COVID-19. Lancet Public Health 2020;5:e240.

6 Raman S, Harries M, Nathawad R, et al. Where do we go from here? a child rights-based response to COVID-19. BMJ Paediatr Open 2020;4:e000714.

7 Kyeremateng R, Oguda L, Asemota O, et al. COVID-19 pandemic: health inequities in children and youth. Arch Dis Child 2021. doi:10.1136/archdischild-2020-320170. [Epub ahead of print: 11 Feb 2021].

8 The Ministry of Health, Labour and Welfare. COVID-19 cases in Japan. Tokyo; 2021. https://www.mhlw.go.jp/stf/covid-19/kokunain ohasseijoukyou.html [Accessed 18 Feb 2022].
9 Mochida S, Sanada M, Shao Q, et al. Factors modifying children's stress during the COVID-19 pandemic in Japan. European Early Childhood Education Research Journal 2021;29:51-65.

10 World Health Organisation. Japan: who coronavirus disease (COVID-19) Dashboard, 2021. Available: https://covid19.who.int/ region/wpro/country/jp [Accessed 18 Feb 2022].

11 Takaku R, Yokoyama I. What the COVID-19 school closure left in its wake: evidence from a regression discontinuity analysis in Japan. $J$ Public Econ 2021;195:104364.

12 Vice-Administrative of Ministry of Education, Culture, Sports, Science and Technology. The implementation status of school closures for measures against COVID-19 pandemic, 2020. Notification from Ministry of education, culture, sports, science and technology. Available: https://www.mext.go.jp/content/202002228mxt kouhou01-000004520 1.pdf [Accessed 18 Feb 2022].

13 Honda C, Yoshioka-Maeda K, Iwasaki-Motegi R. Child abuse and neglect prevention by public health nurses during the COVID-19 pandemic in Japan. J Adv Nurs 2020;76:2792-3.

14 Joshua P, Zwi K, Moran P, et al. Prioritizing vulnerable children: why should we address inequity? Child Care Health Dev 2015;41:818-26.

15 White BP, White BP. The perceived stress scale for children: a pilot study in a sample of 153 children. Int J Pediatr Child Health 2014;2:45-52.

16 Higuchi K. New quantitative text analytical method and KH Coder software. Japanese Sociological Review 2017;68:334-50.

17 Braun V, Clarke V. Using thematic analysis in psychology. Qual Res Psychol 2006;3:77-101.

18 Yamaguchi A, Hosozawa M, Hasegawa A, et al. The coronavirus disease 2019 pandemic and the rights of the child in Japan. Pediatr Int 2022;64:e14913.

19 Questionnaire survey results under COVID-19 pandemic. Okinawa: NPO Okinawa Prefectural school children and childcare support centre, 2020NPO Okinawa Prefectural School Children and Childcare Support Center. Available: https://www.okinawagakudou. com/ files/ugd/b16a48 0f7a1d1989ad4fc0833c6ce0dc1ca2ca.pdf [Accessed 18 Feb 2022]

20 National Online Survey of Children's Well-being During the COVID-19 Pandemic in Japan. CORONA X CODOMO Project, 20202022. Results of the questionnaire studiesNational Center for Child Health and Development. Available: https://www.ncchd.go.jp/center/ activity/covid19_kodomo/related_info.html\#3tab [Accessed 18 Feb 2022]

21 Branquinho C, Kelly C, Arevalo LC, et al. "Hey, we also have something to say": A qualitative study of Portuguese adolescents' and young people's experiences under COVID-19. J Community Psychol 2020;48:2740-52.

22 Idoiaga N, Berasategi N, Eiguren A, et al. Exploring Children's Social and Emotional Representations of the COVID-19 Pandemic. Front Psychol 2020;11.

23 Lee J. Mental health effects of school closures during COVID-19. Lancet Child Adolesc Health 2020;4:421.

24 Townsend E. Debate: the impact of school closures and lockdown on mental health in young people. Child Adolesc Ment Health 2020;25:265-6.

25 Christakis DA, Van Cleve W, Zimmerman FJ. Estimation of US children's educational attainment and years of life lost associated with primary school closures during the coronavirus disease 2019 pandemic. JAMA Netw Open 2020;3:e2028786.

26 Andrew A, Cattan S, Dias MC. Inequalities in children's experiences of home learning during the COVID-19 lockdown in England, 2020.

27 Bayrakdar S, Guveli A. Inequalities in home learning and schools ' provision of distance teaching during school closure of COVID-19 lockdown in the UK. Institute of Social and Economic Research: Essex, 2020.

28 Psacharopoulos G, Collis V, Patrinos HA, et al. Lost wages: the COVID-19 cost of school closures, 2020.

29 Silverman M, Sibbald R, Stranges S. Ethics of COVID-19-related school closures. Can J Public Health 2020;111:462-5.

30 Rajmil L, Hjern A, Boran P, et al. Impact of lockdown and school closure on children's health and well-being during the first wave of COVID-19: a narrative review. BMJ Paediatr Open 2021:5:e001043. 